\title{
OLAFUR ELIASSON, ENTRE REALIDAD \\ Y REPRESENTACIÓN
}

\section{OLAFUR ELIASSON, BETWEEN REALITY AND REPRESENTATION}

\author{
Betty Mirocznik \\ Universidad de Sao Paulo, Brasil \\ betty.arq.18@gmail.com
}

Recepción: 31 de enero de 2020 • Aceptación: 30 de marzo de 2020

RESUMEN

En este artículo se analiza la relación entre el arte y el ser humano desde la construcción del espacio, teniendo como línea conductiva el análisis de la instalación Double Sunset, del artista islandés-danés Olafur Eliasson. Aquí se propone reflexionar sobre algunos entrelazamientos como: naturaleza y artificio, naturaleza y hombre, realidad y representación, ilusión. En este contexto, el lenguaje artístico puede actuar en el estímulo para el diálogo interactivo entre el ciudadano y la ciudad. Para eso, Eliasson trabaja con la forma en que experimentamos y percibimos los espacios para la construcción de un lugar singular a partir de una lectura espontánea y emocional de la obra y no a través de la racionalidad.

Palabras clave: arte, espacio, atmósfera, percepciones, Olafur Eliasson..
ABSTRACT

This article intends to investigate the relationship between art and human being, since the construction of the space, having as a conductive line the analysis of the Double Sunset installation, by the Icelandic-Danish artist Olafur Eliasson. To this end, it is proposed to reflect on some interwoven subjects such as: nature and artifice, nature and man, realization and representation, illusion. In this case, how artistic language may act as a stimulus for interactive dialogue between citizen and the city. Therefore, Eliasson works the way we experience and perceive the spaces for the construction of a singular place from a spontaneous and emotional lecture of the work and not through rationality.

Keywords: art, space, atmosphere, perception, Olafur Eliasson. 
Cuando miro el mundo de hoy, me parece cada vez más que el más grande desafío no es crear sistemas de acuerdo, sino, crear espacio para el desacuerdo; un espacio donde el consenso no es un requisito.

Olafur Eliasson

\section{INTRODUCCIÓN}

En este artículo se analiza la práctica del artista islandés-danés Olafur Eliasson a partir de sus consideraciones sobre el espacio, el lugar y la atmósfera, discutiendo esencialmente las implicaciones de esta narrativa en la experimentación de la instalación por parte del visitante. La construcción de su trabajo parte del uso de la materialidad y la inmaterialidad, tratando la realidad y la ilusión como elementos duales interconectados a través de aparatos artificiales que resultan en una actitud crítica del sujeto en relación a sus percepciones, la conciencia del cuerpo y sensibilidad.

Al elegir temas contemporáneos para la construcción de sus instalaciones - la velocidad de nuestros días, la relación destructiva con la naturaleza, la representatividad e identidad en la sociedad actual, el poder del capital financiero, entre otros-, Eliasson cuestiona y provoca al visitante sacándolo de su zona de confort, proponiendo una reflexión sobre las actitudes y acciones de cada uno en relación al colectivo.

Entre las muchas reflexiones relacionadas con las prácticas del arte contemporáneo, la discusión parte de dos aspectos. El primero trata del momento histórico, cuando el arte se coloca como una actividad que se perpetúa repetidamente, como una práctica de reciclaje y reapropiación de una gran corriente de signos y gestos culturales estéticamente agradables, estableciendo simultáneamente una relación irónica y autorreflexiva. La segunda práctica se refiere a las nuevas tecnologías de sistemas de información, comunicación y procesamiento de imágenes. Insertado en un contexto desterritorializado, el ciudadano globalizado y multicultural se enfrenta a nuevos supuestos artísticos relacionados con la subjetividad y representación.

En respuesta a este mecanismo, surgen prácticas que trabajan los procesos de interpenetración entre ideas y experiencia sensorial, entre sujeto y objeto, presuponiendo una noción de subjetividad difusa y permanentemente expuesta a una multitud de percepciones y posibilidades. Este proceso se ha tensado por los nuevos usos del tiempo en la vida cotidiana, por la globalización, por narraciones fragmentadas y diluidas en el flujo de los medios que siguen principalmente la lógica del capital financiero.

Olafur Eliasson es uno de los artistas que operan en esta clave. Su trabajo trata temas relacionados con la fenomenología de la percepción, aludiendo a las sensaciones corporales y el movimiento del visitante a expensas de características como la velocidad, la homogeneización global, el espacio indeterminado, el exceso de tecnología e imágenes, y la inmersión sin suficiente distancia para ver el esquema de nuestros tiempos. Para este fin, guía su trabajo hacia la investigación de cómo diferentes técnicas y construcciones pueden producir intervenciones con el potencial de aumentar y transformar la percepción humana. Como dice el historiador de arte Jonathan Crary:

[...] el trabajo de Olafur opera en un campo de eventos donde no se produce nada a propósito, donde se crean condiciones para permitir que una zona de virtualidad fluya hasta el límite de su realización. Es una reflexión sobre la movilidad y la relación no jerárquica entre el espectador, el aparato y los elementos sin los cuales los fenómenos no identificables y no localizables se fusionan y subsisten [...] sus instalaciones son deliberadamente transparentes al exponer el componente y funcionamiento de los mecanismos empleados. Por lo tanto, si bien existe este carácter claramente 
desmitificador de la práctica y la concreción de estos elementos, paradójicamente están en desacuerdo con los efectos altamente evanescentes e incluso sublimes que producen estos elementos. Lo material y lo inmaterial coexisten dentro del mismo campo cargado (Crary, 1997: 7).

Olafur Eliasson, entre realidad y representación, se organiza en interludios vivenciales que están interconectados a través de conceptos y análisis de la instalación Double Sunset (1999), construida en la ciudad de Utrecht, Países Bajos. Se observa en esta obra la inexorable existencia de un camino que enfatiza un trayecto completo y procesual del artista en la formalización de la construcción de un espacio singular para cada visitante. En esta trayectoria, nos damos cuenta de que Eliasson está más interesado en las percepciones y experimentos cinestésicos y de movimiento que en la doctrina del ojo.

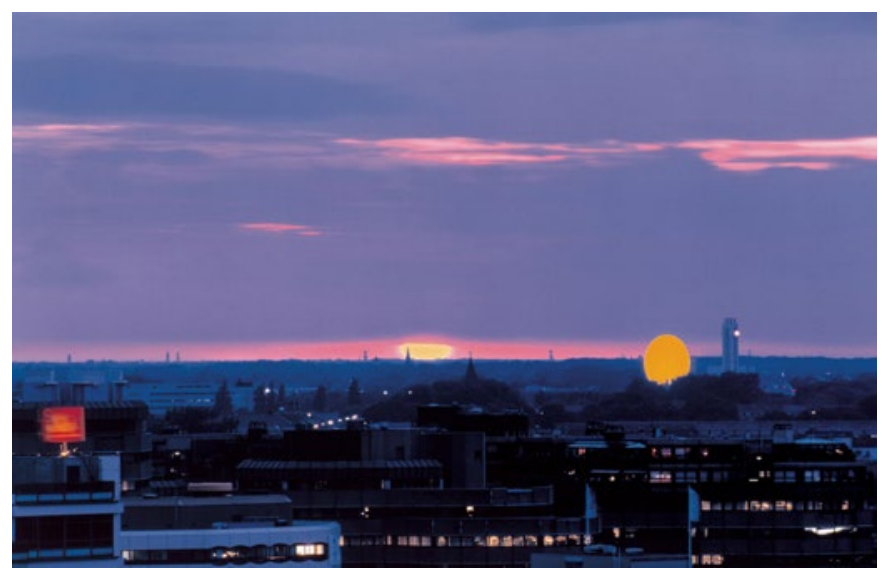

Imagen 1. Double Sunset. Hans Wilschut, 2000.
DONDE ES DÍA, TAMBIÉN ES DE NOCHE

No duermes bajo cipreses, porque no hay sueño en el mundo. El cuerpo es la sombra de las prendas que cubren tu ser profundo [...].

F. Pessoa, Poemas esotéricos.

La instalación Double Sunset, propuso una reflexión sobre algunas relaciones como la naturaleza y el artificio, la naturaleza y el hombre, la realidad y la representación. La construcción de un sol falso con un espectro real ha suscitado en los observadores la conciencia de la existencia de un sol verdadero mientras lo hacía visible. Así se creó una dualidad entre la representación y la realidad algo siniestra. El concepto de siniestro para Freud, se relaciona con la creación de un nuevo real como una posibilidad de revelación en la que todo lo que uno está acostumbrado a ver cambia de significado, lo familiar se vuelve extraño.

En esta obra urbana, el artista creó un gran disco circular de metal corrugado amarillo, de 38 metros de diámetro, ubicado en la parte superior de un edificio industrial cerca de una carretera que conecta los suburbios de Utrecht con el centro. Las personas que pasaban por los alrededores de la instalación experimentaron una doble puesta de sol. Contemplaban simultáneamente un sol real y otro construido, la realidad y el artificio colocados lado a lado creando un efecto de atmósfera desmaterializada. Por la noche, esta superficie fue iluminada por las luces que provenían de un estadio de fútbol ubicado en los alrededores, provocando la ilusión de una puesta de sol que nunca termina, o incluso un sol nocturno. La relación del observador con el trabajo no se ha dado por una recepción pasiva, como un hábito mecánico u observación distante, sino, a partir de la relación entre la obra, el sujeto y la experiencia perceptiva, suscitando cuestiones 
relativas a la realidad y representación como tierra fértil para ser explorada.

[...] tendemos a naturalizar el mundo real hasta el punto en que comienza a parecerse a su propia representación. Al hacer visible la mecánica de sus obras y lanzar el artificio de la ilusión, Olafur señala la relación elíptica entre la realidad, la percepción y la representación de lo real. Sin embargo, mismo cuando su trabajo expone las tecnologías que estructuran los procesos naturales, aún promueve una emoción indeleble, tal vez incluso con connotaciones sublimes (Marcoci, 2001).

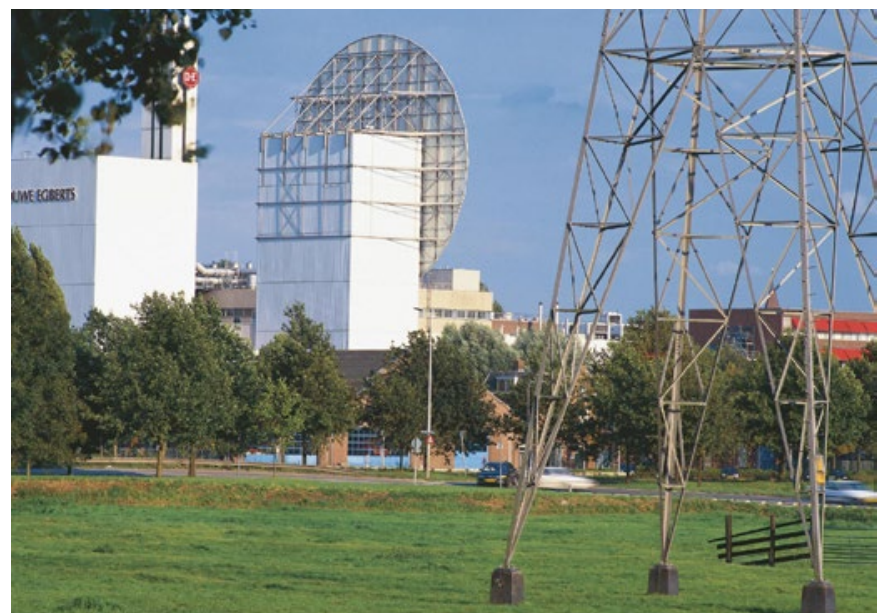

Imagen 2. Double Sunset. Hans Wilschut, 2000.

El trabajo cambió el paisaje y el espacio urbano a su alrededor, promoviendo la potencial socialización de los habitantes que lo observaron desde una perspectiva de movimiento y actividad, y no como arquitectura estática organizada a partir de una jerarquía. Por lo tanto, dependiendo del ángulo desde el que se observó este inusual y bajo sol artificial —en una ciudad de alta latitud, la puesta de sol es un fenómeno lento que se disfruta diariamente durante todo el verano- que se entrelazó al atardecer real, creando una realidad simulada.

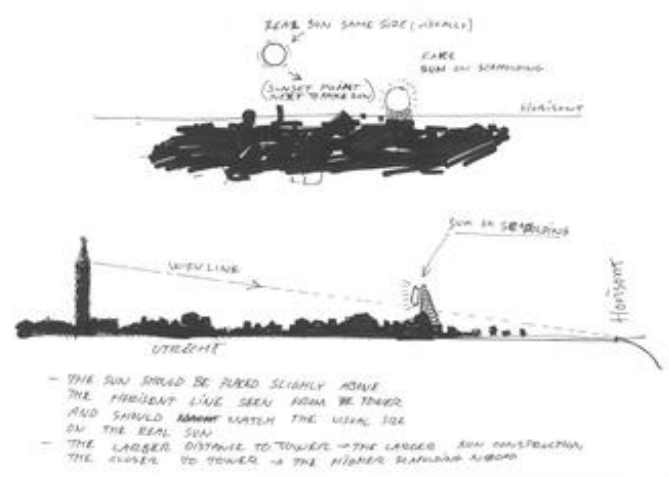

Imagen 3. Double Sunset. Olafur Eliasson, 1999.

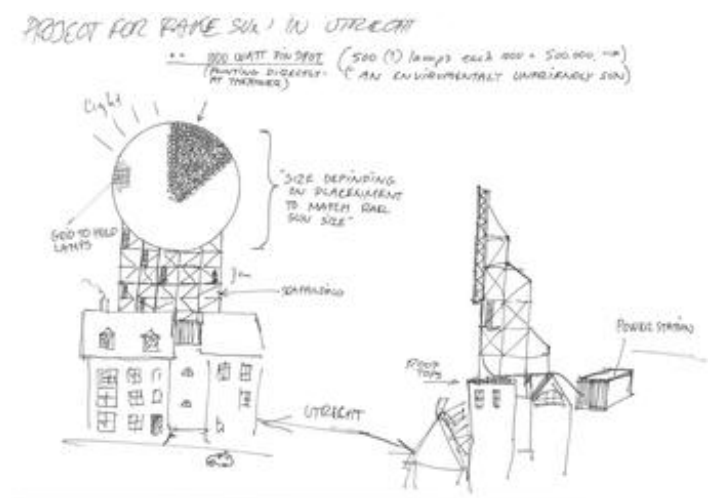

Imagen 4. Double Sunset. Olafur Eliasson, 1999.

De esta forma, Olafur evoca deliberadamente el concepto de lo sublime para evitar su manifestación. Al abordar el fenómeno como arte y hecho, desmitifica las características del sublime en las artes - como la mediación y la representación-, y revela la actividad científica. Al hacerlo, impide deliberadamente 
cualquier relación directa o de contemplación de la naturaleza como algo trascendente. En esta narración, lo sublime operaría no como un objeto sino como una disposición del espíritu, a partir de la cual una representación ocuparía el juicio reflexivo del sujeto. Vuelvo aquí al reflejo de Fabbrini,

[...] el sentimiento del sublime elevaría la fortaleza del alma por encima de su nivel medio, permitiéndo descubrir dentro de nosotros una facultad de resistencia de un tipo totalmente diferente que nos fomentaría a medirnos con la aparente omnipotencia de la naturaleza (Fabbrini, 2017: 56).

En este sentido, el trabajo de Eliasson abarca la relación del sujeto con el entorno. El artista opera en espacios urbanos para hacer que las ciudades sean visibles para sus habitantes que, en su mayor parte, ya no perciben su modo de funcionamiento y tienden a reconocer el ambiente como algo inmutable y reconfortante. Muchos ven el espacio urbano como una imagen externa con la que no tienen conexión, la ciudad se convierte en una imagen mental en detrimento de un lugar de interacción y compromiso. En este contexto, el lenguaje artístico puede actuar como un estímulo para el diálogo interactivo entre el observador y su entorno, promoviendo la unificación entre el arte y la experiencia de tal manera a inspirar y beneficiar la vida de sus habitantes.

Aparte del reconocimiento del ambiente urbano, la instalación sugiere cuestiones sobre nuestros pensamientos representativos, en que la naturaleza es entendida como algo aislado. En esta intervención, incluso el sol poniente puede ser reemplazado por un outdoor que encubre el sol todos los días, camuflandolo sin dejar vestigio.

La instalación Double Sunset abrió la posibilidad de un diálogo sobre el aquí y ahora, entre nosotros y el mundo, en un conjunto de intercambios que suceden desde la intersubjetividad del trabajo. Evoca un diálogo con nuestra existencia al llamar la atención sobre la necesidad de estar siempre despierto, mismo cuando deberíamos dormir.

En esta instalación, el artista cuestiona la forma de vida en la sociedad contemporánea en permanente estado de atención. Por lo tanto, la duplicidad creada entre el sol real y el sol artificial, y la situación que se despliega por la noche cuando el foco brillaba en el círculo creado, como un sol nocturno, suscitó la reflexión sobre el concepto de tiempo, velocidad, exceso de claridad y conexión permanente de nuestros días, además, del peso de la cultura de la vigilancia.

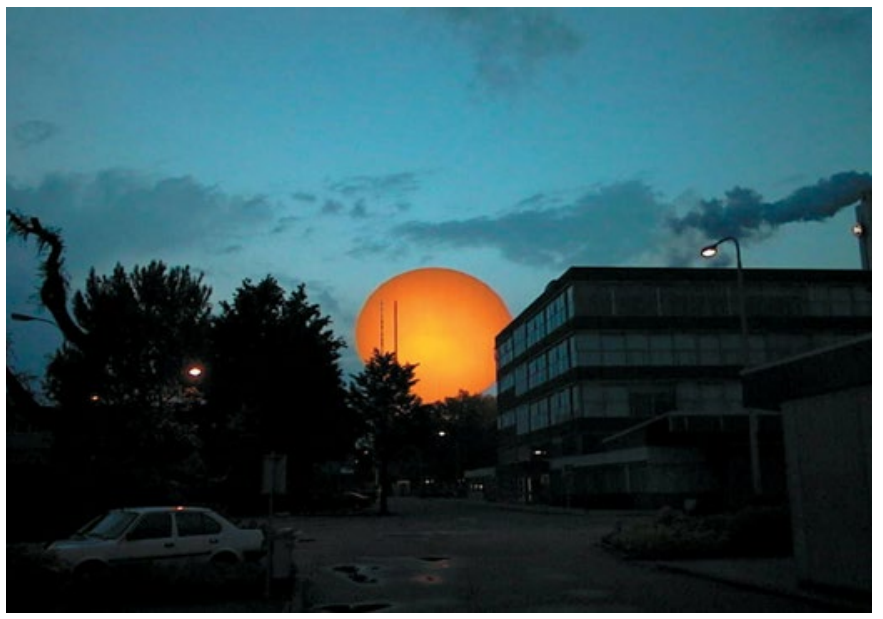

Imagen 5. Double Sunset. Olafur Eliasson, 2000.

Eliasson volvió al tema del inusual sol de Utrecht en la instalación Weather Project (2003). El trabajo tuvo lugar en el hall de entrada -Galería de Turbinas - del Tate Modern, Londres. La obra consistió en un semidisco metálico estructurado por andamios e iluminado por cientos de lámparas similares a las utilizadas en la iluminación urbana. Estas lámparas emitían luz en una frecuencia tan estrecha que los colores, excepto el amarillo 
y el negro, se volvieron imperceptibles para los visitantes. Se instalaron trescientos paneles de espejo cerca del techo de la galería, que, además de duplicar el semidisco que formaba un sol, también reproducían y reflejaban el espacio y los visitantes de la instalación. La obra ponía los visitantes en un campo fenomenológico que los involucrara directamente, enfatizando la desfamiliarización y la desmitificación, creando una nueva dinámica entre el sujeto, el tiempo y el entorno.

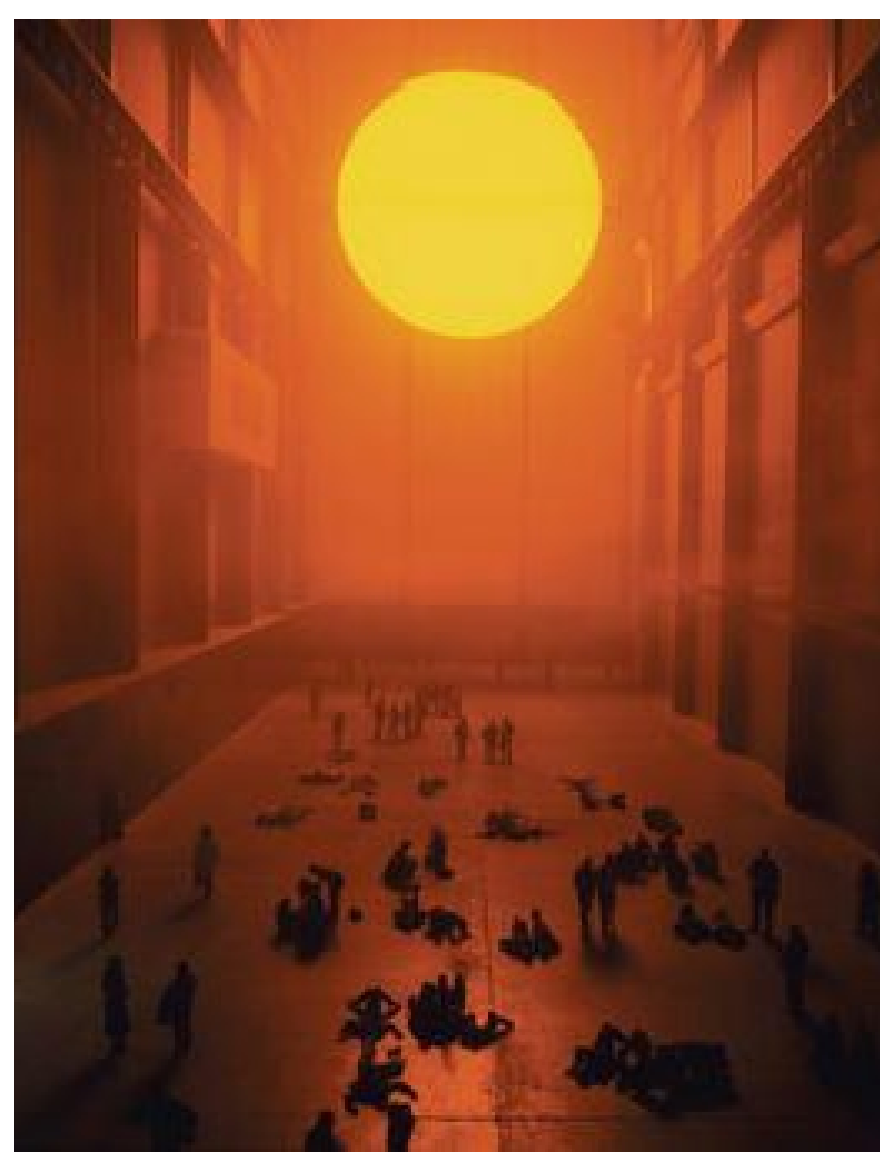

Imagen 6. Weather Project. Andrew Dunkley y Marcus Leith, 2003.
Los puntos planteados por las instalaciones de Eliasson son similares a las consideraciones de Jonathan Crary, que denomina el tiempo de la vida contemporánea $24 / 7$, un tiempo vivido 24 horas por día, los siete días de la semana, como un tiempo de indiferencia, donde el dormir ya no es necesario. Un tiempo alineado con cosas inertes y atemporales que producen algunas paradojas, como el reemplazo del sueño por la vigilia y la destrucción del día por la oscuridad. El asolamiento como condición de luminosidad - excepto cuando es funcional-, cumple con la lógica de consumo del capitalismo global, como afirma,

[...] la inscripción generalizada de la vida humana en la duración sin descanso, definida por un principio de funcionamiento continuo. Es un tiempo que ya no pasa más, apartado del reloj. Más allá del vacío del slogan, la expresión $24 / 7$ es una redundancia estática que no permite ninguna imbricación con las texturas rítmicas y periódicas de la vida humana. Evoca un esquema arbitrario e inflexible de una semana de duración, vaciado de cualquier desdoblamiento de la experiencia, acumulativa o no [...] un ambiente 24/7 aparenta ser un mundo social, pero de hecho es un modelo no social, con rendimiento de la máquina - y una suspensión de la vida que no revela el costo humano requerido para mantener su efectividad (Crary, 2016).

Esta dinámica de mercado, gobernada por la combinación de lo público y lo privado, de la vida cotidiana y los medios institucionales, y subordinada a una financiarización excesiva, disuelve los límites entre lo personal y lo profesional, el entretenimiento y la información. La globalización, en esta economía de atención 24/7, opera como una homogeneización de los comportamientos, no existir nada en la cultura y la naturaleza que no haya sido transformado y contaminado según los médios e intereses de la industria de consumo y entretenimiento 
contemporánea. En este contexto, el sueño resulta ser la última barrera, la única característica natural que resiste y que el capitalismo no puede eliminar. En este sentido, debe considerarse que el advenimiento de internet y las comunicaciones digitales tuvo un impacto sustancial en la financiarización y mercantilización, imponiendo un nuevo comportamiento en las esferas de la vida social e individual.

En esta nueva condición contemporánea, es fácil ver que la estandarización de experiencias en tan amplia escala ha llevado a la pérdida de la identidad del sujeto. El exceso de imágenes con que somos bombardeados contribuyen a un presente congelado y desprovisto de futuro, una sociedad subyugada a un régimen definido por Jonathan Crary como $24 / 7$, que denota la destrucción del día tanto como la oscuridad de la noche, del sueño como la última frontera de lo inútil, o como una forma de resistencia. Este proceso de incapacitación de la experiencia promueve una masificación y despersonalización del individuo frente a su capacidad cognitiva y participativa.

Según Según Jonathan Crary, es evidente que la discrepancia entre el mundo de los hombres y el funcionamiento de los sistemas globales no ocurre más, por lo contrario,

afirma que son esos los sistemas capaces de ocupar nuestras horas de vigilia.

\section{PERCEPCIONES CONTENDIENTES}

Retorno a la reflexión sobre las asociaciones activadas por los procesos de interpretación del sujeto en relación al objeto artístico para tratar la contaminación entre el arte y la vida y como una experiencia en la que la ilusión y la realidad están indiscerniblemente conectadas. Para Olafur Eliasson, no hay precedencia de lo real sobre la representación, porque, desde su punto de vista, el mundo no está dado, sino construido.
Sus producciones parten de una narrativa compleja que involucra preguntas relacionadas con la ciencia y la filosofía, pero sólo se materializan con el disfrute del público. En última instancia, se invita al visitante a percibirse a sí mismo al construir el trabajo, lo que resulta en trabajos paradigmáticos. En este sentido, el sujeto, aunque genera efectos en el medio ambiente, se ve afectado por él. Es, por lo tanto, un tema mixto, el cuerpo como observador y productor, inmerso en un sistema de interdependencia dinámica. La instalación Your Water Horizon Horizon (2009), construida en el 21st Century Museum of Contemporary Art en Kanazawa, Japón, ejemplifica esta discusión.

El trabajo fue compuesto por un reflector dirigido a un prisma que separaba la luz blanca en los colores del espectro luminoso. Estos colores se proyectaron en las aguas de una piscina circular que los reprodujo a lo largo de las paredes de la sala de exposiciones, en forma de arcoíris. Se colocó una varilla conectada a un pedal dentro del agua, que cuando era activada por el visitante, producía pequeñas ondas en el agua que hacían vibrar la proyección del arcoíris. El objeto artístico moldeaba la sala con una atmósfera que invitaba a la experiencia corporal y estética obtenida del envolvimiento táctil con la fisicalidad de la luz que sensibiliza la experimentación de lo nuevo.

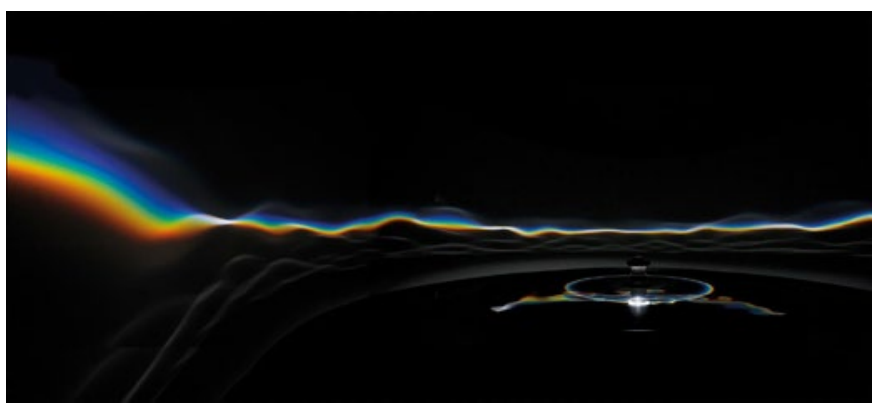

Imagen 7. Your watercolor horizon, Olafur Eliasson, 2009. 
Se encuentra en las obras de Eliasson la desmitificación de los efectos efímeros y luminotécnicos que crean las zonas de virtualidad. Por la concreción de estos elementos, expone el sistema constructivo y los aparatos sin ocultar la forma en que se ensamblaron las instalaciones. Por lo tanto, la revelación de estos procesos rompe con las condiciones habituales de percepción, falsifica la realidad en lugar de aclararla, desmaterializa el espacio por la ilusión de movimiento y fluidez, utiliza recursos evanescentes y cromáticos, añadidos por los usos de efectos obtenidos de luz, entre muchos otros. Para Jochen Volz, quien comisarió una exposición del artista en Brasil en 2011,

Su trabajo deja en claro que gran parte de lo que percibimos no tiene existencia física, externa, sino que está dentro de nuestro sistema sensorial y en el cerebro [...]. Las instalaciones de Olafur funcionan como herramientas que cambian nuestra visión del mundo, y el disfrute lúdico de su trabajo no es más que la alegría de percibirnos, aprender y entender a nosotros (Volz, 2011: 38).

Parte de ahí el aspecto surrealista que se encuentra en sus producciones, que reproduce en gran medida elementos naturales y los confronta con los que se encuentran en la naturaleza, creando una práctica en la que la ilusión está interconectada con la realidad. En las propias palabras del artista,

Estamos presenciando un cambio en la relación tradicional entre realidad y representación, por lo que ya no evolucionamos del modelo (maqueta) a realidad, sino de modelo a modelo, al tiempo que reconocemos que en realidad ambos modelos son reales, por lo que podemos trabajar de manera muy productiva con la realidad experimentada como un conglomerado de modelos, porque en lugar de considerar el modelo y la realidad como modalidades polarizadas, ahora funcionan en el mismo nivel. Los modelos se convirtieron en coproductores de la realidad (Wisnik, 2012: 237).
Para Wisnik, la relación tradicional entre realidad y representación debe entenderse a partir de los cambios de concepto de significado en la posmodernidad, la hipertrofia de la imagen en la sociedad de consumo y la virtualización acelerada en el uso de nuevas tecnologías digitales,

[...] en el caso de Olafur, en lugar de reforzar este efecto de artificialidad como una pérdida total del referente, las obras buscan crear un campo de igualdad para estos casos, en la medida que dejan de ser tratados como polaridades duales. De ahí su enfoque en el tema de la participación de los visitantes como condición de la experiencia de las obras de arte. Lo que significa que estas obras solos se realizan como negociaciones intersubjetivas necesarias entre el artista, el espacio y el público (Wisnik, 2012: 238).

Esta percepción sensorial del espacio es impactante, ya que se ve afectada por algo sin contornos precisos, en el que la percepción de los materiales, las dimensiones, los límites y las reacciones provocadas son completamente diferentes para cada individuo. Esto evita las polaridades binarias, abarcando al sujeto y al objeto en una operación simultánea en la forma en que nos relacionamos con el entorno se desborda en la aprensión retiniana hacia la fenomenología construida a través de la atmósfera. Este concepto se identifica regularmente como un sentimiento o estado de ánimo asociado con un lugar, persona o cosa en particular, sin cualquier referencia a alguna característica espiritual, sino a algo producido por nosotros. En este sentido, la atmósfera se percibe de manera difusa y periférica, no por observación precisa y consciente, sino como un espacio alineado con un conjunto de características indefinidas y distribuidas espacialmente.

Para aclarar esta discusión tomemos como ejemplo la instalación Feelings are Facts (2010), concebida por Eliasson en colaboración con el arquitecto chino Ma Yansong. La intervención 
es una obra site specific - fue diseñada específicamente para ocupar una de las galerías de la UCCA (Ullens Center for Contemporary Art) en Beijing-.

La sala blanca de la exposicion, midiendo aproximadamente 60 por 20 metros, estaba llena de una niebla artificial que recibía luz de una rejilla compuesta por lámparas fluorescentes de colores fijadas al techo de la sala. Estas luces caían sobre la niebla creando campos en los colores rojo, verde y azul. Cuando estos haces de luz se superponían, formaban zonas de transición en tonos de cian, magenta y amarillo. Además de este juego óptico desorientador, hubo una intervención en la arquitectura de la sala, que tenía el techo bajado y el suelo inclinado por medio de una larga rampa construida en la entrada, que de forma gradual, se empinaba hacia la parte posterior del espacio. El proyecto trabajó en la combinación perceptiva y conceptual del individuo basada en elementos presentes en la mayoría de las instalaciones del artista, como la luz, las sombras, el color, el viento y la niebla, utilizados frecuentemente en la construcción de la atmósfera deseada por el artista.

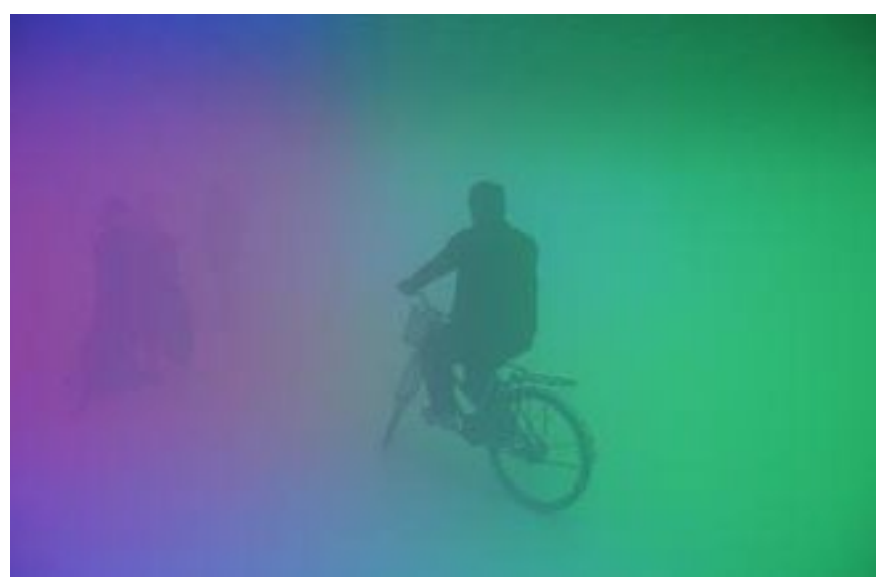

Imagen 8. Feelings are fact. Olafur Eliasson, 2010.

\section{CONSIDERACIONES FINALES}

Las instalaciones de Olafur Eliasson ofrecen a los visitantes la oportunidad de expandir sus capacidades perceptivas y sensoriales, estimulando una actitud crítica en relación a la realidad circundante. Es a través de la experiencia que el visitante se enfrenta con la construcción del espacio, con la conciencia corporal y con el paso del tiempo. Es a partir del acortamiento de las distancias que separan el sujeto del objeto que ocurre la experiencia con el ambiente y la construcción de un lugar.

La obra elegida para esta discusión, la instalación Double Sunset, propone el análisis de varios de los temas propuestos por el artista como la creación de la realidad como una construcción subjetiva, colocando la cuestión de la artificialidad de la naturaleza y los filtros culturales como un paradigma de percepción. Hay que considerar también que la obra puede considerarse como site specific ya que la ciudad de Utrecht ofrece las condiciones arquitectónicas y urbanas necesarias para el disfrute y observación del visitante del proyecto expositivo.

En este sentido, las instalaciones se experimentan en su esencia material y espacial de una manera singular. Teniendo en cuenta que vivimos en una cultura de control y velocidad, eficiencia y racionalidad, en la que se subestiman las experiencias y sensaciones en comparación con los aspectos de comprensión conceptual, intelectual y verbal, es esencial que haya proyectos artísticos que ofrezcan resistencia, una actitud crítica en relación con la realidad de la sociedad contemporánea. 
EL ORNITORRINCO TACHADO • No. 11 - México • UAEMéx • mayo - octubre 2020

\section{REFERENCIAS}

Crary, J. (1997). The Cuirious Garden in der Kunsthalle Basel. Schwabe \& Co, Basel: Verlag-Basel.

Crary, J. (2016). 24/7: Capitalismo tardio e os fins do sono. São Paulo, Ubu Editora.

Eliasson, O. (1999). “Double Sunset”. Disponible en: https:// olafureliasson.net/archive/artwork/WEK101384/double-sunset

Fabbrini, R. (2017). "Estética e Crítica da arte em Jean-François Lyotard”. En O que nos faz pensar,vol. 26, núm. 40.

Marcoci, R. (2001). Projects 73: Olafur Eliasson. New York: The Museum of Modern Art.

Pessoa, F. (2014). Poemas esotéricos. Porto: Assírio \& Alvim.

Tate (2003). "Olafur Eliasson: The Weather Project, about the installation”. Disponible en: http://www.tate.org. uk/whats-on/tate-modern/exhibition/unilever-series/ unilever-series-olafur-eliasson-weather-project-o

Volz, J. (2011). Seu corpo da obra. São Paulo: Edições SESC.

Wisnik, G. (2012). Dentro do nevoeiro: diálogos cruzados entre arte e arquitetura contemporânea. Tesis de Dosctorado. Faculdade de Arquitetura e Urbanismo da Universidade de São Paulo. 